\title{
¿Por qué mata el cáncer?
}

\author{
Anduro Corona Iván ${ }^{1}$ \\ ${ }^{1}$ Centro de Investigación en Alimentación y Desarrollo
}

\section{Resumen}

El objetivo de este artículo es informar a los pacientes oncológicos y a sus cuidadores sobre el comportamiento celular del cáncer a partir de preguntas comunes como ¿qué es el cáncer?, ¿por qué las células del cáncer afectan nuestro cuerpo?, ¿por qué hay células de cáncer en distintas partes del cuerpo?, ¿̇cómo afecta el cáncer a nuestro cuerpo? y iqué hacer para fortalecer el sistema inmune?. Las respuestas a estas preguntas pretenden acercar información asequible y clara para las personas interesadas por entender los procesos relacionados con el cáncer. En los cuales el fortalecimiento del sistema inmune a través de la nutrición oncológica es uno de los aspectos cruciales en el mantenimiento de las funciones vitales.

Palabras clave: cáncer, nutrición, sistema inmune, metástasis, diferenciación celular.

\section{Why does cancer kill?}

\section{Abstract}

This article aims to inform cancer patients and their caregivers about the cellular behavior of cancer, based on common questions such as what is cancer? Why do cancer cells affect our body? Why are there cancer cells in different parts of the body? How does cancer affect our body? And what to do to strengthen the immune system? The answers to these questions are intended to provide accessible and clear information for those interested in understanding the processes related to cancer. In which the strengthening of the immune system through oncological nutrition is one of the crucial aspects of the maintenance of vital functions.

Keywords: cancer, nutrition, immune system, metastasis, cell differentiation. 


\section{INTRODUCCIÓN}

La supervivencia de los pacientes oncológicos en México ha mejorado gracias al avance en el diagnóstico, el tratamiento del cáncer, el conocimiento de la nutrición y los estilos de vida. Es común escuchar y leer sobre los esfuerzos que hacen los científicos por mejorar los tratamientos para el cáncer, para aumentar la esperanza y la calidad de vida, somos muchos, quienes desde diferentes frentes estamos comprometidos con esa tarea. Sin embargo, hay un tema del que no se escribe, ni se habla, ya que puede resultar preocupante para los pacientes: saber cómo el cáncer puede causar la muerte. El objetivo de este artículo es informar a los pacientes oncológicos y a sus cuidadores sobre el comportamiento celular del cáncer.

Pero ¿qué es el cáncer? El cáncer es una enfermedad en la cual las células anormales se dividen sin control y pueden invadir partes cercanas del cuerpo, o lejanas, usando el sistema circulatorio o linfático. Hay muchos tipos de cáncer primario. Se le llama carcinoma cuando el cáncer inicia en la piel o en el recubrimiento de los órganos internos. Se refieren a sarcoma cuando el cáncer comienza en los huesos, cartílago, grasa, músculo, vasos sanguíneos u otro tejido conectivo. La leucemia es un tipo de cáncer que inicia en donde se forma la sangre, como la médula ósea, y causa la multiplicación de las células no diferenciadas. El linfoma y el mieloma múltiple son canceres que comienzan en las células del sistema inmune. Los canceres del sistema nervioso central, comienzan en el cerebro y en la médula espinal.

¿Por qué las células del cáncer afectan nuestro cuerpo? La diferenciación celular es un nombre que usan los científicos para hablar del proceso por el que una célula inmadura se convierte en una célula madura con funciones específicas. En este sentido, podemos entender a una célula indiferenciada como una célula inmadura, ya que tiene lo necesario para convertirse en quien quiere ser, pero no ha recibido las instrucciones para definirlo. Por su parte, a las células bien diferenciadas, podemos compararlas con una célula madura, que ya ha recibido instrucciones para dedicarse a una tarea específica. En el caso del cáncer, la diferenciación celular se refiere a qué tanto se parece un tumor a la parte sana del cuerpo de donde se desarrolla. Una célula del cáncer bien diferenciada es similar a una célula normal y tiende a crecer más lentamente que una célula de cáncer pobremente diferenciada o no diferenciada. En el cáncer, las células no diferenciadas remplazan a las células sanas impidiendo que se desarrollen las funciones normales de la parte del cuerpo donde está el cáncer.

¿Por qué hay células de cáncer en distintas partes del cuerpo? Las células cancerosas se desprenden del tumor original (primario), viajan a través del sistema sanguíneo o linfático y forman un nuevo tumor en otros órganos o tejidos del cuerpo. Al proceso por el que las células de cáncer se diseminan desde el lugar donde se formaron por primera vez, a otra parte del cuerpo se le llama metástasis. Es importante saber que el nuevo tumor metastásico es del mismo tipo que el tumor primario. Por ejemplo, si el cáncer de mama se disemina a pulmón, las células cancerosas del pulmón son células de cáncer de mama.

En el caso del cáncer de hígado, la mayoría de los casos no empezó en el hígado, sino que inició en otras partes del cuerpo como mama, colon, recto, riñón, esófago, pulmón, piel, ovario, útero, páncreas o estómago. Después algunas de estas células viajaron hasta el hígado, en donde crecieron nuevos tumores, parecidos al primero (metástasis). Es importante saber que las células de los tumores primarios tienen funciones diferentes a las células del hígado, cuando los tumores metastásicos o propios crecen, impiden el funcionamiento adecuado del hígado. La disfunción hepática provoca que se acumulen sustancias tóxicas generadas en el cuerpo, provocando la muerte.

Es de resaltar que los diferentes tumores primarios, hacen metástasis principalmente a pulmón, hígado y cerebro. Aunque estos tumores pueden invadir otras partes del cuerpo.

¿Cómo afecta el cáncer a nuestro cuerpo? El cáncer usa una serie de estrategias para asegurar su supervivencia: buscan alimentos (inducción de angiogénesis), se camuflan (evasión de la respuesta inmune), se perpetúan (activación de la telomerasa), se reproducen (metástasis), entre otras.

Para explicar el efecto de la metástasis, podemos comparar el funcionamiento del cuerpo humano con un automóvil, el cual necesita la computadora (cerebro), el cableado que lleva las señales a las diferentes partes del auto (nervios), tuberías (sistema circulatorio y linfático), así como los sistemas críticos (riñones, hígado, pulmones y cerebro), que le permiten al automóvil o al cuerpo, según se trate, funcionar adecuadamente. Cuando hay metástasis en una o algunas de estas partes, es posible que simplemente se impida el correcto funcionamiento de esa parte del cuerpo, principalmente por impedimento mecánico. Por ejemplo, un tumor metastásico en pulmón puede crecer tanto que impide la respiración, provocando la muerte al paciente, o bien, un tumor metastásico en cerebro puede presionar la parte del cerebro encargada de enviar las señales que controlan la respiración.

La obstrucción mecánica indirecta se presenta cuando hay metástasis en los principales órganos de depuración y detoxificación como los riñones y el hígado. El hígado ayuda 
a tu cuerpo a digerir la comida, almacenar energía y eliminar desechos tóxicos. La metástasis al hígado puede provocar obstrucción del flujo de la bilis e insuficiencia hepática, una complicación muy peligrosa.

De forma adicional el cáncer metastásico puede liberar sustancias que impiden el correcto funcionamiento del cuerpo, que, en conjunto con los efectos secundarios de los tratamientos contra el cáncer, provocan que los nutrientes de los alimentos no puedan ser aprovechados. Todo esto hace que los pacientes se sientan débiles y sin apetito, lo que empeora su estado de salud por desnutrición y mayor susceptibilidad a infecciones debido a un sistema inmune debilitado.

¿Qué hacer para fortalecer el sistema inmune? Es de suma importancia que a la par del diagnóstico y tratamiento médico, se tenga un seguimiento en nutrición oncológica brindado por personal capacitado en esta área. En el cáncer, la exposición a contaminantes, la deficiencia de nutrientes específicos, los factores hormonales y metabólicos, están relacionados todos con la alimentación. En general una dieta variada, equilibrada y saludable, así como un consumo de probióticos de forma regular contribuyen a un buen funcionamiento del sistema inmune. La terapia nutricional debe estar basada en el estado nutricional del paciente, en sus hábitos alimentarios, sus horarios, sus actividades y preferencias culturales. La distribución de la energía debería ser distribuida en menos de 30\% de grasas insaturadas, 55\% de carbohidratos provenientes de avena, arroz integral y frutas, y $15 \%$ de proteína para evitar el peso elevado y baja masa muscular. Fortalecer el sistema inmune por medio de la alimentación es una tarea central en el proceso de atención de pacientes oncológicos.

\section{BIBLIOGRAFIA}

a) Hanahan, D. y Weinberg, R.A. 2011. Hallmarks of cancer: next generation. Cell 144. DOI 10.1016/j. cell.2011.02.013.

b) AARP. 2020. American Association of Retired Persons. Disponible en https://healthtools.aarp.org/es/health/ metastasis-en-el-higado, consultado el 20 de octubre de 2020.

c) Shirvani, S. 2020. Disponible en https://reflexion.com/ how-does-a-person-die-from-metastatic-cancer/, consultado el 23 de octubre de 2020.

d) $\mathrm{NCl}$. 2020. National Cancer Institute. Disponible en https://www.cancer.gov/publications/dictionaries/cancerterms/def/differentiation, consultado el 23 de octubre de 2020.

e) Limon-Miro, A.T., Lopez-Teros, V., Astiazaran-García, H. 2017. Dietary Guidelines for Breast Cancer Patients: A Critical Review. Advances in Nutrition, 8: 613-623.

f) Vilaplana I Batalla, M. 2010. Nutrición y sistema inmunitario: una relación muy estrecha. Nutrición Ámbito Farmacéutico. 29: 75-80. 